\title{
Voluntariado hospitalar: um estudo sobre a percepção dos profissionais de saúde
}

\author{
André Luís Ferreira Moniz \\ Escola Superior Professor Paulo Martins \\ Faculdade de Ciências Sociais e Tecnológicas \\ Tereza Cristina Cavalcanti Ferreira de Araújo \\ Universidade de Brasília
}

\begin{abstract}
Resumo
Fortemente incentivados como modo de atuação frente aos problemas sociais atuais, os serviços voluntários são freqüentemente referidos como enriquecedores para o indivíduo. Todavia, quando dirigidos à área da saúde, questiona-se o suporte técnico e emocional assegurado aos voluntários, porque sua ausência ou fraqueza pode suscitar sofrimento psíquico para o agente, ou prejudicar o atendimento e as relações voluntário-profissional. Para melhor compreender a natureza do voluntariado e o modo como é percebido pelos integrantes da equipe de saúde, a pesquisa foi realizada em duas etapas. Na primeira delas, 29 profissionais responderam a um questionário sobre a percepção destes serviços no hospital. Na segunda, 14 destes profissionais foram entrevistados. Os relatos foram submetidos à análise de conteúdo temática e ao software Alceste. Embora existam diferenças entre profissionais, a avaliação geral dos serviços voluntários foi positiva, sendo que alguns identificaram limitações. Discute-se a necessidade de maior capacitação e supervisão dos voluntários e apontam-se sugestões para futuras investigações.
\end{abstract}

Palavras-chave: voluntariado; hospital; profissionais da saúde; percepção

\begin{abstract}
Volunteer work in hospitals: a study about health professional's perception. Strongly encouraged as a way to act on present-day social problems, volunteer services are usually reffered as enriching for the person involved. However, when related to health, volunteer's technical and emotional support is questionable, for its absence or weakness may induce psychological suffering in the agent or jeopardize the interventions provided and the volunteer-professional relations. In order to better understand the nature of volunteer work and the way it is perceived by health team members, a two-part study was carried out. At the first part, 29 professionals answered a questionnaire about their perception concerning the volunteer work in the hospital; at the second, 14 of them were interviewed. Data were submitted to a thematic content analysis and to the software Alceste. Although the results indicated differences among professionals, the general evaluation of the volunteer services was positive, in spite of the limitations identified by some team members. The need for more qualification and supervision of the volunteers is discussed, and suggestions for future investigations are pointed.
\end{abstract}

Keywords: volunteer work; hospital; health professionals; perception.

$\mathrm{N}$ o âmbito internacional, as repercussões do movimento em prol da atuação voluntária podem ser facilmente reconhecidas com a proclamação da Organização das Nações Unidas (ONU) estabelecendo o Ano Internacional do Voluntariado em 2001. No Brasil, o vertiginoso aumento da oferta e procura por serviços voluntários nos mais diferentes setores culminou com a sanção da Lei do Voluntariado, número 9.608, de 19 de fevereiro de 1998, que define o voluntariado como sendo uma atividade não-remunerada prestada por alguém a uma entidade pública ou instituição sem fins lucrativos com objetivos cívicos, culturais, educacionais, científicos, recreativos ou de assistência, dissociada de qualquer obrigação de natureza trabalhista, previdenciária ou afim, regulamentada por um termo de adesão estabelecido entre a entidade e o prestador do serviço.

A partir de um levantamento efetuado em parceria com o Instituto Brasileiro de Opinião Pública (Ibope), estima-se que $22,6 \%$ da população dedicam parte do seu tempo em ações de ajuda. Cerca de $16 \%$ prestam serviços voluntários por seis horas mensais, em média, envolvendo-se em atividades que não exigem 
maior qualificação (53,7\%). A maior proporção de voluntários encontra-se na faixa-etária de 34 a 54 anos. Não foi encontrada diferença significativa no grau de instrução entre voluntários e não-voluntários; porém, pode-se observar que dentre aqueles que prestam este tipo de serviço, é expressivo o número de pessoas com segundo grau completo. Verificou-se que as camadas mais populares da sociedade, com renda familiar média de cinco salários mínimos por mês, são as mais envolvidas. Nenhuma adesão religiosa específica foi significativa, no entanto, a atuação voluntária parece crescer à medida que aumenta a freqüência a cultos religiosos. O setor da saúde recebe $6,5 \%$ do tempo dedicado aos serviços voluntários (Landin \& Scalon, 2000).

$\mathrm{Na}$ esfera social, as questões vinculadas ao voluntariado se inserem na discussão sobre o terceiro setor, considerado como um modelo emergente e em plena expansão, que deve ser diferenciado do primeiro setor (governo de Estado), pois não possui fins públicos e também não deve ser confundido com o segundo setor (mercado), pois, embora mobilize capital privado, não visa o lucro. Suas ações podem ser formalizadas, quando abrangem serviços ligados a organizações, e informalizadas, quando englobam trabalhos sem relação com uma organização (Fernandes, 2000; Domeneghetti, 2001).

No campo do conhecimento, comportamentos de ajuda são estudados por várias ciências há muito tempo. Biologia, Sociologia, Antropologia e Psicologia, apenas para mencionar algumas, reúnem vastas investigações sobre este importante componente da vida biológica, social e humana.

Partindo dessa perspectiva multidisciplinar, dois eixos teóricos têm se destacado no estudo das ações voluntárias: na Sociologia e na Psicologia Social. Assim, do ponto de vista sociológico, estuda-se o voluntariado e suas relações com instituições sociais, fatores demográficos, relações com o grupo familiar e com a religião (Wilson, 2000).

Quanto à Psicologia Social, investiga-se o voluntariado no campo dos comportamentos pró-sociais que são entendidos, genericamente, como ações individuais ou de grupo para beneficiar outras pessoas. Penner, Dovidio, Piliavin e Schroeder (2005) propuseram uma perspectiva multinível para compreender esses comportamentos. Assim, no nível micro, são estudadas as origens das tendências pró-sociais com destaque para a perspectiva da teoria evolucionária, as bases genéticas e biológicas da ação, processos de desenvolvimento e fatores de personalidade. No nível meso, discutem-se as relações de ajuda em condições específicas, sendo foco de análise as situações e os mecanismos que levam uma pessoa a ajudar outra. Por fim, no nível macro de análise, enquadram-se as ações voluntárias e os comportamentos de cooperação. Neste nível, o voluntariado é abordado em seu contexto organizacional e considerado como uma atividade desenvolvida de maneira planejada por um período extenso de tempo. Especificamente, são pesquisadas as razões e motivações para se voluntariar, os mecanismos de manutenção do voluntariado, as relações com os comportamentos organizacionais e as conseqüências dessa atividade para o voluntário.

Das possíveis conseqüências da atividade para o voluntário, destaca-se, por exemplo, aquela apontada por Midlarsky (1991), que considera que a ajuda a outras pessoas constitui uma forma de enfrentamento aos agentes estressores daquele que ajuda. Esse comportamento, não permite que um indivíduo se sinta vítima, mas se torne um agente que continua tendo capacidade para agir, além de reagir. Como agente, ele pode ajudar a si próprio promovendo a distração dos próprios problemas, aumentando o senso de valor e significado da própria vida, aumentando o senso de auto-competência, melhorando o senso de humor e promovendo a sua integração pessoal. Todavia, indagações básicas sobre o ajudar permanecem obscuras e muitas iniciativas ainda serão necessárias para esclarecê-las. Nesse sentido, merecem destaque o Primeiro Congresso Brasileiro de Voluntariado, organizado em 2001, e o Primeiro Congresso Internacional do Voluntariado, de 2003, que promoveram a divulgação de propostas e pesquisas sobre o voluntariado.

\section{Identidade e motivações do voluntariado}

Rubin e Thorelli (1984) destacam que as motivações para tornar-se voluntário se distribuem ao longo de um contínuo entre dois pólos: o altruísmo absoluto e o egoísmo absoluto. Considerando-se que a ocorrência prática dos dois extremos é socialmente impossível, estipula-se a noção de altruísmorelativo em que os comportamentos serão julgados mais ou menos altruístas dependendo do grau em que foram motivados pela expectativa de benefícios. Embora muitos voluntários não admitam sua necessidade de recompensa, tais expectativas parecem esclarecer quanto às diferenças motivacionais. Em outras palavras, quanto maiores os benefícios para o voluntário - como desenvolver relacionamentos, oportunidade de ensinar e aprimoramento pessoal - mais prolongada será a sua permanência na atividade.

Existiriam quatro modalidades de gratificação voluntária: (a) benefício coletivo, caracterizado pelo esforço para beneficiar grupos pequenos ou grandes; (b) incentivo seletivo, representado pela obtenção de prestígio social, prazer e realização; (c) aumento do capital humano, que envolve educação ou atividade que incrementam habilidades (experiência de trabalho e treinamento profissional); (d) motivações altruístas, entendidas freqüentemente como um auto-sacrifício sem aparente recompensa pessoal (D’Braunstein \& Ebersole, 1992; Rubin $\&$ Thorelli, 1984).

As motivações para se prestar serviços voluntários variam quanto à idade e às expectativas de recompensa. Voluntários mais jovens buscam desenvolver habilidades lucrativas que resultem em reforço econômico, enquanto que os mais velhos procuram uma troca ou convívio reforçador social. Quanto à variável gênero, o trabalho voluntário feminino parece ter um impacto positivo maior que o dos homens, remetendo ao papel de cuidadora atribuído à mulher (Zweigenhaft, Armstrong, \& Quintis, 1995).

Ao que tudo indica, o voluntariado pode servir a diferentes funções pessoais, sociais e psicológicas para um mesmo indivíduo ou para indivíduos diferentes. Assim sendo, é possível distinguir seis modalidades de atuação.

Expressão de valores. Mantém a coerência com valores e convicções pessoais importantes, bem como com a disposição da personalidade. São exemplos desta motivação aquelas chamadas de altruístas, ou imbuídas de obrigações morais. 
Ajustamento social. Reflete a influência normativa dos amigos, familiares ou de outras pessoas significantes e que também são voluntárias. Controlado por recompensas ou punições sociais, o voluntário sofre pressão para fazer parte de uma rede social como membro importante.

Defesa do ego. Ajuda a enfrentar conflitos, ansiedades e incertezas com relação aos valores pessoais e competências, ou seja, é uma autoproteção para neutralizar conclusões indesejáveis ou ameaçadoras sobre o self.

Conhecimento. Proporciona novas idéias ou satisfação de uma curiosidade intelectual. Também serve para ganhar, exercitar ou praticar conhecimentos e habilidades.

Carreira. Está relacionada à obtenção de benefícios para a trajetória profissional, servindo como preparação para uma nova carreira ou para manutenção de habilidades relevantes.

Engrandecimento. Está associado ao desenvolvimento pessoal ou à melhoria da auto-estima ou do humor (Clary \& Snyder, 1991; Clary et al., 1998).

\section{Voluntariado no hospital}

Na saúde, demandas cada vez mais prementes e de grande amplitude social - do nível curativo ao nível preventivo e da promoção do desenvolvimento humano - não são atendidas de modo eficaz pelo Estado, apesar dos esforços empreendidos. Existem carências de toda ordem - sobretudo de recursos humanos - cujas nefastas conseqüências podem ser minimizadas com a oferta de serviços voluntários. Além de trazer satisfações no plano individual, o voluntariado pode favorecer a instituição que o promove. Especificamente no meio hospitalar, fortemente estruturado e cientificista, este tipo de contribuição incrementa a humanização dos cuidados (Cantril, 1991; MacEarchern, 1962).

Para Wells, DePue, Buehler, Lasater e Carleton (1990):

A pré-suposição do potencial dos voluntários nos esforços de promoção à saúde é baseada na suposição de que as pessoas que compõem determinada organização (ou subgrupo cultural) estarão familiarizadas com o ambiente cultural no qual as mudanças do comportamento de saúde ocorrerão. Tais voluntários poderiam ajudar a assegurar compatibilidade entre o programa de promoção de saúde e os elementos desta organização, pois seriam capazes de traduzir os conceitos técnicos de saúde em termos compreensíveis para seus pares e evitar falhas culturais que o staff profissional pode não ter consciência. Voluntários podem ter acesso imediato a seus pares e membros de sua rede social e assim abordar os pontos de mudança. (p. 24)

Um estudo feito em unidades de atendimento a portadores de câncer indicou que o trabalho voluntário é valorizado por pacientes e enfermeiros, ao fornecer suporte psicossocial aos enfermos e familiares e suporte instrucional com informações e resolução de problemas práticos no meio hospitalar (FuscoKarmann \& Tamburini, 1994). No entanto, tanto a experiência prática quanto as reflexões de alguns especialistas alertam sobre a necessidade de organização e gerenciamento adequado da atuação voluntária, especialmente no que concerne à saúde. Reconhecidos, em algumas ocasiões, como membros da equipe hospitalar, os voluntários podem ser alvo da preocupação da direção do hospital que aloca recursos financeiros para recrutar e supervisionar suas atividades. Sugere-se, até mesmo, um recrutamento que privilegie o desenvolvimento pessoal do candidato, em associação com as necessidades e características de cada hospital (D’Braunstein \& Ebersole, 1992; Jimenez \& Jimenez, 1990; Miller, Powell, \& Seltzer, 1990).

Omoto e Snyder (1995) analisaram situações de acompanhamento a doentes crônicos por voluntários, notadamente em razão de laços de parentesco, injunções legais ou éticas, focalizando o interesse na compreensão das estratégias de enfrentamento, dos recursos disponíveis frente ao estresse e da rede de suporte social.

Vale comentar, ainda, o estudo comparativo realizado por Souza et al. (2003) sobre os aspectos motivacionais para exercer trabalho voluntário em Oncologia, no Brasil e em Portugal. Os autores constataram a existência de um padrão motivacional manifestado independentemente de fatores culturais. Nos dois países, os voluntários são do sexo feminino, pertencem à classe média e, em sua maioria, são pessoas casadas e sem qualificação profissional. Como motivação principal para exercer essas atividades, em ambas as culturas, destacou-se o altruísmo, considerado como comportamento de ajuda, não motivado por acontecimentos adversos externos ou esporádicos. No entanto, cabe mencionar que a opção por este tipo de trabalho está relacionada com um aspecto individualista de resolução de problemas vividos anteriormente, uma vez que, na amostra abordada, 95\% das participantes brasileiras e $83 \%$ das portuguesas informaram histórico pessoal ou familiar relacionado ao câncer.

As pesquisas sobre voluntariado em saúde apontam que, em sua maioria, os indivíduos contam apenas com a própria disposição e empenho, sem preparo ou acompanhamento. Ao contrário do profissional da saúde, que pode se apoiar na formação e no aparato técnico, o voluntário pode se ver exposto ao estresse, tornando-se inadequado e, em casos mais graves, comprometer a assistência ao paciente. Informalmente criticados pelos profissionais e, às vezes, pelos próprios assistidos, os grupos voluntários continuam a desenvolver suas ações esbarrando em frustrações e conflitos, gerando mais custos que benefícios. A fragilidade das relações entre a instituição hospitalar e as associações voluntárias revela-se no pouco controle que se tem sobre o trabalho voluntário, para o qual não é possível ter expectativa de compromisso e qualidade de serviços semelhantes ao grupo profissional com vínculo empregatício. O voluntariado necessita de capacitação e treinamento permanentes. Isto, em especial no que se refere à atuação junto a portadores de doenças crônicas que necessitam cuidados especiais e apoio emocional, como soropositivos e pacientes oncológicos (Jones, 1996; Moniz \& Araújo, 2006; Paradis \& Usui, 1989).

Nos Estados Unidos, desde 1950, a Associação Americana de Hospitais estabelece que o voluntariado deva ser organizado como um grupo formalmente aprovado, que age em conexão com a administração hospitalar para angariar recursos, visando à aquisição de equipamentos específicos, a manutenção de algum setor e até cuidados para "indigentes". O manual de orientação para voluntários desta associação ressalta a necessidade de compreensão do funcionamento institucional 
por parte dos voluntários e o reconhecimento da importância e potencialidade dos serviços voluntários prestados por parte do hospital (MacEarchern, 1962). Paradis e Usui (1989) defendem a reciprocidade entre voluntários e profissionais, uma vez que os primeiros reivindicam mais acesso a informações técnicas sobre a evolução das enfermidades e modos de atendimento, ao passo que os profissionais almejam partilhar as informações que os voluntários detêm sobre as emoções do paciente e sua dinâmica familiar.

No contexto brasileiro, cabe destacar o trabalho empreendido por Araújo, Maia e Oliveira (1997), visando descrever os aspectos motivacionais da atuação voluntária em Oncologia a partir do relato de seis entrevistados a respeito dos seguintes tópicos: características, funções e percepção sobre a natureza do serviço voluntário; relação com o trabalho remunerado e tempo despendido com o voluntariado; motivação e gratificações; relacionamento com o grupo de voluntários, familiares dos pacientes e a equipe de saúde; fatores que influenciam a permanência ou o abandono na atividade; experiências anteriores em voluntariado; utilização de estratégias de enfrentamento para alívio de possíveis dificuldades decorrentes; organização formal do trabalho voluntário; religião; perfil do voluntário ideal; percepção e meta-percepção social e história de vida relacionada ao câncer. Dentre os resultados obtidos, verificou-se que os sujeitos ingressaram na atividade após terem passado por uma experiência de adoecimento pessoal ou na família, encontrando bem-estar e auto-realização no exercício do voluntariado.

Mais recentemente, Moniz e Araújo (2006) focalizaram as conseqüências psicológicas da atuação voluntária para o próprio agente prestador de serviço aplicando o Inventário de Sintomas de Estresse de Lipp e Guevara e o Inventário de Burnout de Maslach em 39 voluntários afiliados a instituições de apoio a pacientes oncológicos ou soropositivos. Conjuntamente, os participantes tiveram baixos escores de estresse e burnout. Entretanto, oito participantes apresentaram sintomas de estresse e quatro manifestaram níveis elevados de burnout no que concerne à despersonalização e exaustão emocional. Estudo semelhante foi executado por Bakker, Zee, Lewig e Dollard (2006), no qual se relacionaram fatores de personalidade como proteção para o burnout entre voluntários que acompanhavam pacientes terminais.

Considerando, portanto, os interesses vinculados à problemática do voluntariado na área hospitalar, desenvolveuse uma investigação com o objetivo geral de descrever e compreender a percepção dos profissionais de saúde sobre os serviços prestados por voluntários no contexto hospitalar.

\section{Método}

A pesquisa foi planejada em duas etapas. O projeto foi aprovado pelo comitê de ética da Faculdade de Ciências da Saúde da Universidade de Brasília e pelo comitê de ética da Secretaria de Saúde do Distrito Federal. A coleta de dados foi conduzida com a colaboração de auxiliares de pesquisa. Cada profissional foi abordado individualmente nas duas etapas e solicitado a expressar sua concordância por meio da assinatura do Termo de Consentimento Livre e Esclarecido.
A primeira etapa teve como objetivo específico conhecer a percepção dos serviços voluntários, incluindo descrição e avaliação da atividade, assim como levantar a freqüência da interação do profissional com voluntários, no intuito de identificar os informantes qualificados para participar da segunda etapa. Participaram 29 profissionais de saúde, dos quais 22 nas especialidades de hematologia, quimioterapia e radioterapia, destinadas à Oncologia, sendo seis médicos, nove enfermeiros, um assistente social, dois psicólogos e quatro secretários. Os outros sete participantes exerciam cargos de chefia, direção ou administração. Todos desempenhavam suas funções em um hospital de grande porte no Distrito Federal. Foi desenvolvido e utilizado um instrumento intitulado Percepção dos Profissionais de Saúde sobre a Atuação Voluntária, composto por questões objetivas que avaliavam: (a) a freqüência do contato entre profissional e voluntário nas diferentes áreas do hospital utilizando uma escala de tipo Likert de cinco pontos, de "0" (nunca encontrei), a "4" (sempre encontro); (b) a importância da atuação dos voluntários nas áreas de: apoio e suporte emocional, apoio e contribuições materiais, apoio especializado (cortar cabelo, ajudar nos cuidados de enfermagem, etc.), facilitação da adesão dos pacientes ao tratamento, contato e suporte aos familiares dos pacientes, prestação de informações aos pacientes, promoção de atividades sociais (artes, educação, atividade física, lanche, etc), utilizando uma escala tipo Likert de quatro pontos, de "0" (não se aplica/nunca presenciei) a "4" (útil/importante); (c) a percepção da adequação das relações entre voluntários e os diferentes profissionais no hospital - direção do hospital, médicos, enfermeiros, auxiliares de enfermagem, assistentes sociais, psicólogos e servidores de apoio, para o quê se utilizou uma escala de tipo Likert com quatro pontos, de "0" (não se aplica/nunca presenciei) a "3" (adequada).

Também integravam o instrumento duas perguntas abertas: (1) De modo geral, como você descreveria a atuação dos voluntários com quem tem contato? (2) Como você avalia esta atuação? As repostas às questões estruturadas foram submetidas a análises descritivas de freqüência utilizando o software estatístico SPSS, e as respostas às questões abertas foram analisadas com auxílio do programa Alceste (Ribeiro, 2000).

A segunda etapa da pesquisa teve por finalidade retomar a percepção profissional em uma abordagem qualitativa. Colaboraram 14 profissionais dentre aqueles que haviam participado da etapa anterior, a saber: três participantes que possuíam cargos de chefia, três médicos, um psicólogo, quatro enfermeiros, um assistente social e duas secretárias. Optou-se pela técnica da entrevista semi-estruturada estabelecida por meio de um roteiro mínimo composto pelas seguintes perguntas: (1) Como você descreveria o serviço prestado pelos voluntários neste hospital? (2) Quando você interage com os voluntários? (3) Onde se dá essa interação? (4) Como se dá essa interação? (5) Ela ocorre com que objetivos? (6) Como você avalia os serviços voluntários (contribuições e limitações/dificuldades)? (7) Que outras contribuições os voluntários poderiam trazer? (8) Como você caracteriza os voluntários com quem tem contato? (9) Que medidas poderiam ser tomadas para melhorar sua atuação? (10) Qual seria sua participação ideal? (11) Os voluntários precisam de treinamento? (12) Que conhecimentos, habilidades e atitudes 
precisam ser desenvolvidas?

Os relatos foram gravados em áudio, transcritos e submetidos à análise de conteúdo temática (Bardin, 1977). O material também foi submetido ao programa de análise quantitativa do discurso (Alceste), para identificação das principais categorias e das relações estatísticas entre elas.

\section{Resultados}

\section{Etapa 1: Questionário}

Os locais onde os profissionais relataram maior freqüência de contato com voluntários podem ser listados na seguinte ordem: ambulatório (média $=3,8$ ); corredores e dependências de uso comum $(M=3,6)$; enfermaria $(M=3,8)$; pronto socorro e emergência $(M=1,8)$; e direção e administração do hospital $(M=1,7)$.

Quanto à importância da atuação voluntária para todos os profissionais, encontrou-se a seguinte ordem: atividades sociais $(M=2,8)$; apoio emocional e material $(M=2,5)$; apoio especializado $(M=2,4)$; facilitação da adesão ao tratamento $(M$ $=2,1)$; prestação de informações $(M=1,9)$ e; contato e suporte aos familiares dos pacientes.

Como se pode verificar na Figura 1, no que se refere ao apoio emocional, os profissionais que atribuíram maior importância e utilidade da atuação dos voluntários foram respectivamente: (1) chefias, administrador e secretários; (2) psicólogos, assistente social e secretários administrativos; (3) enfermeiros; (4) médicos. Para apoio material, os psicólogos e o assistente social, chefias e administração e secretária administrativa atribuíram pontuação máxima consensualmente. Foram seguidos pelos enfermeiros, secretários e médicos. Apoio especializado recebeu maior pontuação da secretária administrativa. Seguiram-se: (1) secretários e chefias e administrador; (2) enfermeiros; (3) psicólogos; (4) médicos. O papel do voluntário no estímulo à adesão ao tratamento foi mais valorizado pelas chefias e administrador e pelos psicólogos e assistente social. Os profissionais das outras quatro áreas avaliaram pior, sobretudo os médicos. A mesma tendência se repetiu para apoio e suporte aos familiares dos pacientes. No entanto, os enfermeiros avaliaram um pouco melhor que os secretários, enquanto a secretária administrativa igualou-se aos médicos. Para a prestação de informações ao paciente, os psicólogos e o assistente social atribuíram pontuação máxima, enquanto enfermeiros, secretários e secretários administrativos atribuíram notas semelhantes. Os médicos atribuíram menores pontuações e as chefias e administração consideraram pouco útil ou importante. Por fim, em relação ao item atividades sociais, houve maior concordância para utilidade e importância dos voluntários. Os enfermeiros, psicólogos e o assistente social, secretários, chefias e administrador atribuíram as avaliações máximas, seguidas pelos secretários administrativos e pelos médicos.

Somando-se as médias de cada profissional, cuja pontuação

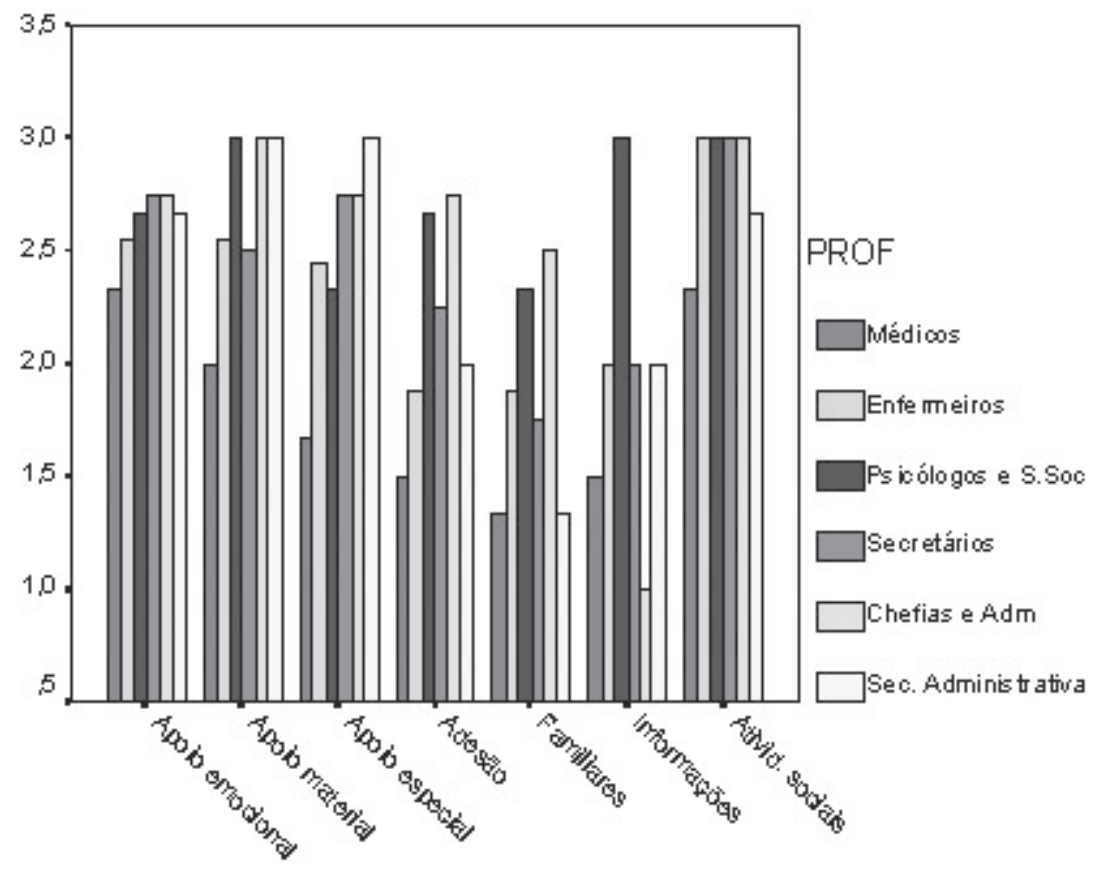

Figura 1. Percepção dos profissionais em relação às categorias de atuação voluntária junto aos pacientes. 
máxima seria 21 (sete itens com avaliação variando de 0 a 3), pode-se dizer que os psicólogos e o assistente social (soma das médias $(\mathrm{sm})=19$ ) avaliaram melhor a atuação voluntária que os outros profissionais. As chefias e o administrador $(\mathrm{sm}=17,75)$, os secretários $(\mathrm{sm}=17)$, a secretária administrativa $(\mathrm{sm}=16,67)$ e os enfermeiros $(s m=16,34)$ tiveram menores escores. Os médicos apresentaram pior avaliação da importância da atuação voluntária $(\mathrm{sm}=12,66)$.

Em relação à percepção global dos profissionais quanto à adequação das relações estabelecidas entre voluntários e os profissionais, percebeu-se que os assistentes sociais foram destacados como os profissionais com os quais os voluntários têm maior adequação $(M=2,2)$. Os demais profissionais foram ordenados da seguinte maneira: auxiliares de enfermagem $(M$ = 2); enfermeiros $(M=1,9)$; servidores de apoio $(M=1,7)$; direção do hospital $(M=1,5)$; médicos $(M=1,4)$; e psicólogos $(M=1,1)$.
A Figura 2 pormenoriza a percepção da adequação das relações entre voluntário e os profissionais de cada área. Como se pode perceber, os médicos atribuíram um número mais reduzido de categorias de atuação voluntária junto a outros profissionais, quando comparados com os secretários, os psicólogos e o assistente social. Os enfermeiros expressaram uma avaliação muito discrepante no que diz respeito à categoria profissional considerada, ao identificar o maior número de serviços prestados junto aos auxiliares de enfermagem e o menor número em relação ao trabalho voluntário realizado em associação aos psicólogos.

A análise das questões abertas do questionário, apoiada pelo Alceste, evidenciou a presença de três categorias relacionadas. As categorias importância do voluntário e valorização do voluntariado relacionam-se moderadamente. Ambas revelam avaliações positivas dos serviços voluntários, com a diferença de a primeira apresentar também avaliações ambivalentes.

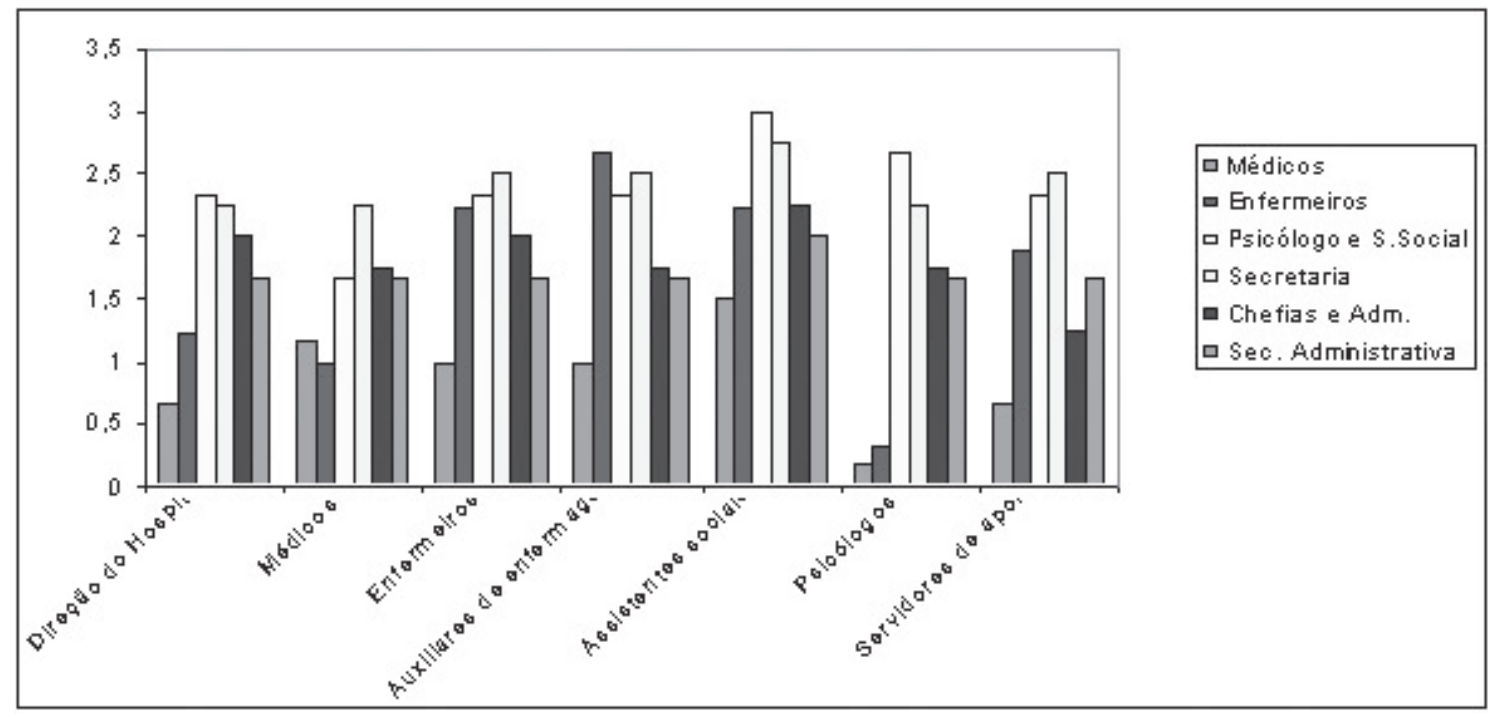

Figura 2. Percepção dos serviços voluntários prestados junto aos profissionais das diversas áreas.

A primeira categoria enfatiza a descrição das características dos voluntários, a segunda enfatiza as atividades prestadas. A terceira categoria denominada senso crítico não se relaciona com as outras duas. Ela aponta as necessidades de aprimoramento deste serviço.

Esta fase da análise também indicou que os profissionais com menos tempo de experiência tendem a valorizar excessivamente os serviços voluntários, comunicando apenas julgamentos positivos. De modo geral, os médicos apresentaram-se como os profissionais que expressaram mais críticas e sugestões de aprimoramento, embora reconheçam a importância dos serviços voluntários.

\section{Etapa 2: Entrevista}

Os relatos submetidos à análise de conteúdo temática geraram as seguintes categorias: atendimento ao doente; características e perfil do voluntário; valorização e estímulo ao voluntariado; interação com o profissional; limitações e problemas com a atividade voluntária; capacitação do voluntário; sugestões dos profissionais.

Este procedimento de análise forneceu subsídios para a aplicação do Alceste e a interpretação das categorias selecionadas pelo programa, as quais foram divididas em dois blocos não-relacionados: atuação voluntária tradicional e atuação voluntária institucionalizada. O primeiro bloco engloba: as características dos serviços voluntários e sua importância; os traços e características das pessoas que o desempenham, os serviços prestados ao paciente e as dificuldades associadas à atuação no ambiente hospitalar. O segundo bloco abarca o apoio prestado pela associação voluntária, necessidades de organização e administração e o conflito entre o papel do voluntário e o papel do Estado e do Governo.

É interessante ressaltar que os participantes masculinos contribuíram mais para o bloco atuação voluntária tradicional, 
enquanto as mulheres forneceram mais relatos categorizados no bloco atuação voluntária institucionalizada. Houve maior concentração de relatos das chefias nos blocos atuação voluntária institucionalizada e importância do trabalho voluntário.

Em contraposição aos resultados da etapa anterior, os auxiliares de enfermagem e os secretários foram os profissionais que mais enfatizaram as dificuldades da atuação voluntária hospitalar, ao passo que médicos e psicólogos destacaram relatos vinculados à categoria que descreve os traços e características dos voluntários. No bloco atuação voluntária tradicional, encontramse, sobretudo, profissionais mais jovens e profissionais com mais tempo de serviço.

\section{Discussão}

Predominou uma percepção das características positivas dos voluntários entre as diferentes categorias profissionais, apesar das avaliações críticas. Ao destacar uma relação de oposição entre os serviços voluntários e o papel do Estado e do Governo, os profissionais revelaram uma percepção crítica do voluntariado. Forneceram sugestões de aprimoramento, tais como: necessidade de maior integração do voluntário com a equipe de saúde, ampliação dos serviços para outros setores do hospital, aumento da competência nas esferas psicológica, jurídica e de assistência social. Eles julgam que os voluntários deveriam envolver-se mais em atividades de denúncia e reivindicação, da mesma maneira que costumam orientar o paciente quanto ao espaço físico no hospital e a natureza e características do tratamento. Também recomendam a realização de projetos que somem a força dos vários grupos voluntários que ainda se encontram dispersos em uma mesma instituição.

Como decorrência das preocupações dos participantes desta pesquisa, é possível questionar se os serviços voluntários não incorrem no risco de uma "filantropização" da questão social? Aliás, para Landin e Scalon (2000), é necessário criar formas positivas e integrativas de sociabilidade frente à desafiliação social, das quais o voluntariado seria um modo de expressão. Estes autores criticam o fato do voluntariado ser tomado como "panacéia" para a retração do Estado diante dos problemas sociais.

Em síntese, verificam-se duas tendências de avaliação dos serviços voluntários, uma crítica que aponta as limitações e problemas e outra valorativa e estimuladora, demonstrada nas categorias referentes à valorização e estímulo e às sugestões do profissional. Estas tendências não são dicotômicas, pois muitas vezes os profissionais se posicionam de modo ambivalente ou transitam entre uma e outra.

As limitações e os problemas com a atividade voluntária identificados na presente investigação assemelham-se àqueles apontados por Paradis e Usui (1989). Segundo esses autores, os profissionais têm pouco controle sobre os serviços voluntários e têm dificuldades em depender deles com a mesma expectativa de compromisso e qualidade que exigem de outros membros da equipe. Eles criticam a descontinuidade das atividades propostas, salientam a imperativa integração das ações profissionais e voluntárias e reclamam um melhor direcionamento das ações.
Consideram que os voluntários poderiam atuar na identificação das demandas dos pacientes, mediar a relação entre o profissional e a comunidade e ainda fornecer um atendimento mais especializado e de orientação. Então, as análises realizadas permitem concluir que o trabalho voluntário tende a se aproximar do trabalho profissional, constituindo-se em uma categoria que precisa ser incorporada e entendida na instituição hospitalar (Cantril, 1991; Fusco-Karmann \& Tamburini, 1994; MacEarchern, 1962; Wells et al., 1990). Parece pertinente pensar que se por um lado o voluntário deve compreender o funcionamento e necessidades do hospital, por outro lado, este deve compreender a importância e potencialidade do voluntariado para a organização. Essa compreensão recíproca é condição básica para o alcance dos objetivos institucionais.

Futuras pesquisas podem explorar em maior profundidade esta questão acompanhando os treinamentos fornecidos pela instituição ou implementando estratégias de avaliação das necessidades de treinamento. Nesse mesmo sentido, Souza et al. (2003) apontam para esse imperativo, destacando a importância de estudos e ações na área da Psico-Oncologia e uma atenção especial para os aspectos emocionais envolvidos nesse tipo de suporte ao paciente.

A necessidade de capacitação do voluntário pode ser depreendida dos resultados do Alceste e da análise das entrevistas com profissionais. Nota-se que a figura assistencialista vem cedendo lugar à imagem do voluntário responsável e integrado à equipe de saúde e à unidade hospitalar. No entanto, como destacado anteriormente, frente a essa institucionalização, é necessário maior clareza entre aquilo que é papel ou competência do voluntário e aquilo que é dever e compromisso do Estado.

\section{Considerações finais}

De modo geral, tantos os profissionais da área assistencial, quanto aqueles do setor administrativo revelaram uma percepção positiva dos serviços voluntários. Mas, também foram capazes de formular críticas e apontar limitações. Insistiram quanto à necessidade de se refletir sobre as conseqüências decorrentes da resposta do voluntariado às insuficiências do Estado no atendimento às demandas na área da saúde. Enfatizaram a adoção de medidas visando seu aprimoramento, como a integração desses serviços no fluxo de atendimento da instituição de saúde. Em outras palavras, dada a emergência do terceiro setor, o voluntariado não deveria ser valorizado apenas em razão dos interesses econômicos associados. Até porque, para continuar revertendo-se em algo bom e produtivo, a atuação voluntária deve ser acompanhada e avaliada pelas organizações beneficiadas e pelas entidades associativas.

Sugere-se que futuras investigações dêem maior atenção à análise da interação profissional-voluntário no contexto das ações efetivamente realizadas em instituições de saúde. Para tanto, a adoção de técnicas de registro observacional e a constituição de grupos focais compostos por agentes e profissionais da saúde possivelmente constituirão um enriquecimento para esta linha de pesquisa. Da mesma maneira que Sousa e Araujo (2007), defende-se a ampliação dos interesses com a inclusão de estudos 
sobre as práticas comunitárias cada vez mais difundidas em programas sociais.

\section{Agradecimento}

Os autores agradecem o apoio do Conselho Nacional de Desenvolvimento Científico e Tecnológico (CNPq).

\section{Referências}

Araujo, T. C. C. F., Maia, L. M. E., \& Oliveira, D. S. (1997). Voluntariado em oncologia: estudo exploratório [Resumos]. In VII Encontro Nacional dos Psicólogos da Área Hospitalar (Org.), Resumos de comunicações cientificas (p. 44). Brasília: Universidade de Brasília.

Bakker, A. B., Zee, K. I. V. D., Lewig, K. A., \& Dollard, M. F. (2006). The relationship between the big five personality factors and burnout: a study among volunteer counselors. Journal of Social Psychology, 146(1), 31-50.

Bardin, L. (1977). Análise de conteúdo. Portugal: Edições 70.

Cantril, J. G. (1991). Inducing health care voluntarism through sequential requests: perceptions of effort and novelty. Health Communication, 3(1), 59-74.

Clary, E. G., \& Snyder, M. (1991). A functional analysis of altruism and prosocial behavior. In M. S. Clark (Org.), Prosocial behavior (pp. 119-147). Thousand Oaks, California: Sage.

Clary, E. G., Snyder, M., Ridge, R. D., Copeland, J., Stukas, A. A., Haugen, J., \& Miene, P. (1998). Understanding and assessing the motivations of volunteers: a functional approach. Journal of Personality and Social Psychology, 74(6), 1516-1530.

D’Braunstein, S., \& Ebersole, P. (1992). Categories of life meaning for service organization vonlunteers. Psychological Reports, 70, 281-282.

Domeneghetti, A. M. (2001). Voluntariado: gestão do trabalho voluntário em organizações sem fins lucrativos. São Paulo: Esfera.

Fernandes, R. C. (2000). O que é o terceiro setor? In E. B. Ioschpe (Org.), Terceiro setor: desenvolvimento social sustentado (pp. 26-33). São Paulo: Paz e Terra.

Fusco-Karmann, C., \& Tamburini, M. (1994). Volunteers in hospital and home: a precious resource. Tumori, 80(4), 269-272.

Jimenez, M. A., \& Jimenez, D. R. (1990). Training volunteers caregivers of persons with Aids. Social Work in Health Care, 14(3), 73-85.

Jones, S. (1996). Using health promotion to support volunteer workers. Nursing Times, 92(6), 34-35.
Landin, L., \& Scalon, M. C. (2000). Doações e trabalho voluntário no Brasil: uma pesquisa. Rio de Janeiro: Sete Letras.

MacEarchern, M. T. (1962). Hospital organization and management. Berwyn, Illinois: Physicians' Record Company.

Midlarsky, E. (1991). Helping as coping. In M. S. Clark (1991). Prossocial Behavior (pp. 238-263). Thousand Oaks, California: Sage.

Miller, L. E., Powell, N. G., \& Seltzer, J. (1990). Determinants of turnover among volunteers. Human Relations, 43(9), 901-917.

Moniz, A. L. F., \& Araujo, T. C. C. F. (2006). Atuação voluntária em saúde: autopercepção, estresse e burnout. Interação, 10(2), 235-243.

Omoto, A. M., \& Snyder, M. (1995). Sustained helping without obligation: motivation, longevity of service, and perceived attitude change among Aids volunteers. Journal of Personality and Social Psychology, 68(4), 671-686.

Paradis, L. F., \& Usui, W. N. (1989). Hospice staff and volunteers: issues for management. Journal of Oncology, 7(1/2), 121-140.

Penner, L. A., Dovidio, J. F., Piliavin, J. A., \& Schroeder, D. A. (2005). Prosocial behavior: multilevel perspectives. Annual Review of Psychology, 56, 365392.

Ribeiro, A. S. M. (2000). Alceste: análise quantitativa de dados textuais. Manuscrito não-publicado, Universidade de Brasília, Brasília.

Rubin, A., \& Thorelli, I. M. (1984). Egoistic motives and longevity of participation by service volunteers. Journal of Applied Behavioral Science, 20(3), 223235.

Sousa, M. A., \& Araújo, T. C. C. F. (2007). Voluntariado: uma mudança paradigmática na prestação de serviços comunitários. In LAPsiS (Org.), V Jornada Internacional de Representações Sociais, Anais dos Trabalhos Completos. Recuperado em 19 de novembro de 2007, de http://www. gosites.com.br

Souza, C. B., Bacalhau, M. R. N., Moura, M. J., Volpi, J. H., Marques, S., \& Rodrigues, M. R. G. (2003). Aspectos da motivação para o trabalho voluntário com doentes oncológicos: um estudo colaborativo entre Brasil e Portugal. Psicologia: Saúde e Doenças, 4(2), 267-276.

Wells, B. L., DePue, J. D., Buehler, C. J., Lasater, T. M., \& Carleton, R. A. (1990) Characteristics of volunteers who deliver health education and promotion: a comparison with organization members and program participants. Health Education Quaterly, 17(1), 23-35.

Wilson, E. (2000). Volunteering. Annual Review of Sociology, 26, 215-240.

Zweigenhaft, R. L., Armstrong, A., \& Quintis, F. (1995). The motivations and effectiveness of hospital volunteers. Journal of Social Psychology, 136(1), $25-34$.

André Luís Ferreira Moniz, doutorando em Psicologia Social, do Trabalho e das Organizações pela Universidade de Brasília, é professor na Escola Superior Professor Paulo Martins e na Faculdade de Ciências Sociais e Tecnológicas. Endereço para correspondência: SHCES 703, Bloco A, Apto 202 (Cruzeiro Novo); Brasília, DF; CEP: 70655-731. Tel.: (61) 3254-2806 / 9121-3426. E-mail: profandremoniz@gmail.com Tereza Cristina Cavalcanti Ferreira de Araújo, doutora em Psicologia pela Université de Paris X Nanterre (França), é professora associada na Universidade de Brasília e Bolsista do Conselho Nacional de Desenvolvimento Científico e Tecnológico-CNPq. E-mail: araujotc@unb.br 